\title{
Drought Stress and its Effect on Amazonian forest Dynamics Model Projections
}

\author{
T. N. S. Karfakis ${ }^{1 *}$, A. Andrade ${ }^{2}$, C. Volkmer-Castilho ${ }^{3}$, D. R. Valle ${ }^{4}$, E. Arets ${ }^{5}$, and P. Van Gardingen ${ }^{6}$
}

${ }^{1}$ Division of Biology, Imperial College of Science, Technology and Medicine, Ascot, SL5 7PY, United Kingdom

${ }^{2}$ Biological Dynamics of Forest Fragments Project, Institute for research in the Amazon (INPA), Manaus, Amazonas, Brazil

${ }^{3}$ EMBRAPA, Amazonas, Brazil; ${ }^{4}$ Faculty of Ecology, Duke University, Durham, NC, USA

${ }^{5}$ Subdivision of Forest and Landscape Ecology, Wageningen Agricultural University, Wageningen, Netherlands

${ }^{6}$ School of Geosciences, Edinburgh University, Edinburgh, Scotland, United Kingdom

\section{Article History}

Manuscript No. AR821a

Received in $27^{\text {th }}$ June, 2014

Received in revised form $26^{\text {th }}$ December, 2014

Accepted in final form $7^{\text {th }}$ January, 2015

\section{Correspondence to}

"E-mail: theokarfak@gmail.com

\section{Keywords}

Drought, forest dynamics model, non-flooded Amazonian forest

\begin{abstract}
The large diversity of tree species of tropical moist forests relative to temperate zones and their biomass storage capacity and how these are maintained over extended periods of time have been subjects of particular interest. Simulation models of forest dynamics are increasingly used to gain insights regarding the long term effect of both direct and indirect anthropogenic impacts on these forests. If such models cannot maintain a stable coexistence of species and biomass dynamics in undisturbed forest simulations modeling results might be misleading with potentially deleterious implications. An effort is described, based on a nested experimental design by use of simulation modeling and examination of long term permanent sample plots data (PSP's) along with climatic records that had the objective to assess the importance of periodic drought disturbance in the maintenance of compositional and biomass stability over a 100-year period on the dynamics of the primary forest and on the sustainability of timber harvesting in the tropical non flooded forests of the Amazon basin. This is done using two separately recalibrated models within the SYMFOR modeling framework. It is shown that periodic drought stress within the limits of natural environmental fluctuation can have a significant influence on the simulated biomass dynamics of these forests considering trees $>10 \mathrm{~cm}$ dbh but not on the dynamics of functional composition. Implications of these were found to be highly significant.
\end{abstract}

\section{Introduction}

Amazonian forests are estimated to be some of the most diverse forest ecosystems on the planet in terms of tree species diversity and also to harbor a great deal of the global biological diversity (ter Steege et al., 2003). They also contain significant amounts of biomass in relation to many other terrestrial ecosystems of the world (Lewis et al., 2009) and at the same time are an important sink for carbon and other related pollutants causing anthropogenic global warming by trapping these directly in the biomass of the forest and mostly the trees (Malhi et al., 2004).

The exact mechanism by which the forest is maintained in its seemingly undisturbed natural state is proposed to be some form of disturbance regime either allogenic, autogenic or a combination of some form (Arets 2005; Bamphlyde et al., 2005; Burrows, 2000).

With respect to compositional diversity Arets (2005) proved the intermediate disturbance hypothesis to be true for a tropical rainforest community in Guyana which would indicate that some form of relatively low but frequent disturbance unlike anthropogenic disturbances such as selective logging or shifting cultivation is responsible for this diversity. The nature of this disturbance still remains open to question however. If found true this disturbance would also be a factor to consider in terms of the issue of the maintenance of biomass also. It has been proposed that periodic death of moribund trees in these forests creates an adequate level of disturbance for the perpetuation of all species present and at proportions observed (Bamplhyde et al., 2005; Burrows 2000; Van dam 2001). This however is not the only way gaps can be created in the canopy and adjacent vegetation disturbed.

For the Amazon basin in particular two major non anthropogenic allogenic stress factors have been identified as having a significant impact on the biomass dynamics and therefore 
potentially the compositional dynamics of the forest.

The first is blow-downs a form of invisible hurricane that periodically affect these forests uprooting trees and creating disturbance in the canopy in general (Nelson et al., 1994). The second is drought stress leading to the death of trees especially canopy and emergent ones and thereby periodically increasing the natural gap creation rate relative to its complete absence (Williamson et al., 2000; Phillips et al., 2009; Karfakis and Andrade, 2013).

The objective of this research is to prove that periodically naturally occurring droughts are the major factor in determining the apparently observed stable biomass and tree species coexistence of primary Amazonian terra firme forests and consequently has a significant influence also on the dynamics of these in response to selective logging. To achieve this a forest dynamics model within the SYMFOR framework (Phillips and van Gardingen, 2001) is used. The same model is separately recalibrated using data from permanent sample plots established in two areas differing in ecological and climatic conditions.

Our hypothesis is that a model that includes a periodically re- occurring drought stress pulse based on relevant long term monitoring data predicts medium to long term biomass and functional composition dynamics more accurately in relation to one that does not and therefore drought is a significant factor in the shaping of currently observed patterns in the dynamics of both undisturbed forest vegetation and one subjected to selective logging

\section{Materials and Methods}

\subsection{Study areas}

The study utilized permanent sample plot data derived from two areas on non-flooded Amazonian forest. The first is in the state of Amazonas and more specifically the Manaus region while the second is the state of Madre de Dios in Peru (Figure 1). The life zone for both areas is classed as tropical moist forest (Holdrige 1978).However the Madre de dios area is much drier with an average annual rainfall of only $1568 \mathrm{~mm}$ in relation to $2258 \mathrm{~mm}$ in Manaus and a dry season (defined as the number of months with $\leq 200 \mathrm{~mm}$ of rain) of 4-5 months as opposed to 1-2 months in Manaus (Satyamurty et al., 2010). The climate in both regions is Af in the Koppen scale (Sombroek, 2001). The native forests of both Amazonas and Madre de dios has both deciduous and broadleaf trees in the overstory (Laurance et al., 2004; Erwin 1985). Edaphic (Oxisols/yellow latosols) and topographic conditions (gently rolling) were similar across (Quesada et al., 2006)

The forest of the Amazonas area is exceptionally rich in tree species (more than 280 tree species considering trees $>10 \mathrm{~cm}$ d.b.h) with a consequently very low dominance on a per hectare basis (in relation to the Madre de dios site with only 130 tree species per hectare on average considering trees $>10 \mathrm{~cm}$ d.b.h (ter Steege et al., 2003).

There are also considerable variations in terms of biomass and its dynamics (Malhi et al., 2004) as well as stand structure for forests of these sites (ter Steege et al., 2003). More specifically forests of the Madre de dios area have much lower stem density in relation to Amazonas (400 stems $\geq 10 \mathrm{~cm}$ dbh in Madre de dios viz. 500 stems in Manaus). Also the forests of Manaus exhibit a decreased dynamism of biomass turnover in relation to Madre de Dios (1.8 $\mathrm{Mg} \mathrm{C} \mathrm{ha}^{-1} \mathrm{a}^{-1}$ on average in Manaus vs $4 \mathrm{Mg} \mathrm{C} \mathrm{ha}^{-1} \mathrm{a}^{-1}$ in Madre de Dios )

\subsection{Data sets}

Permanent sample plot (PSP) data were made available from the Manaus region in Amazonas state, Brazil and the Madre de Dios in Peru. They are described briefly bellow.

The series of plots in Manaus are clustered in four locations. The first is the Adolpho Duke Forest reserve located $26 \mathrm{~km}$ outside the city of Manaus $\left(02^{\circ}, 55^{\prime} \mathrm{S}, 59^{\circ}, 59^{\prime} \mathrm{W}\right)$. Castilho et al. (2006) provide details of the data and the environment of the plots.

The second is the Biological Dynamics of Forest Fragments Project (BDFFP) undisturbed forest plots located $90 \mathrm{~km}$ outside the city of Manaus (2॰51'31.24" S; 59 53'17.36" W). They have been monitored at various intervals since 1981 with the last campaign made available in 2004. Quesada et al. (2006) provide details of the data and the environment of these plots.

The third series of plots was the TEAM network early warning system for nature permanent sample plots. Plots are located 100

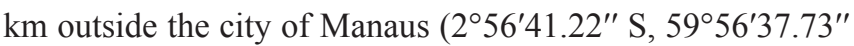
W). Quesada et al. (2006) provide details of the data and the environment of these plots.

The fourth series of plots was the Precious Woods Amazonas ltd permanent sample plots which is located $250 \mathrm{~km}$ outside the city of Manaus ( $\left.2^{\circ} 57^{\prime} \mathrm{N}, 58^{\circ} 42^{\prime} \mathrm{W}\right)$. Karfakis et al. (2013) and Wellhofer (2002) provides details of the data and the environment of these plots respectivelly.

The series of plots in Madre de Dios, Peru are clustered in two locations $120 \mathrm{~km}$ outside the city of Puerto Maldonado in the Madre de Dios province of Peru (12 $40^{\prime} 59.20^{\prime \prime} \mathrm{S}, 69^{\circ} 13^{\prime} 1.50^{\prime \prime}$ W). They are known as Tambopata and Cuzco Amazonico. Quesada et al. (2006) provide details on the datasets and the environment of these plots.

\subsection{Tree species grouping}

Because of the high diversity of tree species present in the dataset, species where assigned to one of 9 ecological groups 
based wood density and adult stature class (Table 1). All tree species where classified a priori using all possible combinations of three bole wood specific gravity $\left(\mathrm{g} \mathrm{cm}^{-3}\right)$ and three adult stature classes (maximum potential height classes in meters). The result of this was nine groups. The approach was originally developed and tested for rainforest in Malaysia (Kohler et al., 2000) and has been validated and used for Neotropical rainforest for purposes of forest dynamics modeling (Arets, 2005; Silva, 2004; Kamesheidt et al., 2001).

\subsection{The baseline model}

The baseline models in our case was separately recalibrated for the forests of the Manaus and Madre de Dios regions using the relevant permanent sample plot data. The decision to calibrate separately came as a consequence of the significant differences in tree species composition, stand structure and dynamics and associated differences in physical environment. Two other model variants were created by fine tuning for each area. All trees $\geq 10 \mathrm{~cm}$ dbh where included in the process. A brief description of the baseline model for both areas which is described more extensively elsewhere (Karfakis et al., 2013) follows.

The growth, recruitment and mortality functions where calibrated for each species group. The growth submodel (equation 1) predicts annual diameter growth, I (in centimeters per year) of an individual tree, as a function of tree diameter at breast height, $\mathrm{D}$ (in centimeters), and a competition index

$$
\mathrm{I}=\mathrm{D}\left(\mathrm{a}_{\mathrm{o}}+\mathrm{a}_{1} \mathrm{e}^{-\mathrm{a} 2 \mathrm{D}}\right)+\mathrm{a}_{3} \mathrm{C}+\mathrm{a}_{4}
$$

$\left(20 \times 20 \mathrm{~m}^{2}\right.$ subplot basal area in $\left.\mathrm{m}^{2}\right)$.

Where, $\mathrm{a}_{0} \ldots \mathrm{a}_{4}$ are model parameters, $\mathrm{D}$ is the diameter at breast height, $\mathrm{C}$ is the diameter independent competition index and $\mathrm{e}$ is the mathematical constant represented by this symbol

Annual recruitment probability, $\mathrm{F}$, is predicted for each $20 \times 20$ $\mathrm{m}^{2}$ subplot a function of the growth, I, of a hypothetical tree with $10 \mathrm{~cm}$ diameter centered in the middle of $20 \times 20 \mathrm{~m}^{2}$ grid square The probability of recruitment $(\mathrm{F})$ of new trees in a grid-square of $100 \mathrm{~m}^{2}$ for the Para model and $400 \mathrm{~m}^{2}$ for the

$$
\mathrm{F}=\mathrm{r}_{1}+\mathrm{r}_{2} \mathrm{I}_{10}
$$

Manaus and Puerto Maldonado models depends on the light availability in that grid-square (equation 2).

Where $r_{1} \ldots . r_{2}$ are model parameters, $I_{10}$ is the diameter growth rate in $\mathrm{cm}$ per year of the hypothetical tree of the minimum d.b.h of $10 \mathrm{~cm}$ in the center of a $20 \times 20 \mathrm{~m}^{2}$ grid square. The growth rate is predicted using the growth model described for a tree with the same diameter at the minimum d.b.h threshold of $10 \mathrm{~cm}$.

A model parameter, Ti represents the time required (in years) for in growth as the number of years required for a tree to grow from seed to a d.b.h of $10 \mathrm{~cm}$. It is used in the simulation when an area of ground is cleared of seedlings, for example when the soil surface is mechanically scarified and compacted during log extraction. This is different for all three areas and ecological group within each area.

Finally the annual mortality probability (as a percentage) on an annual basis based on size (d.b.h) for each individual tree $\geq 10$

$$
\begin{aligned}
& \mathrm{mi}=1-\left[1-\frac{\text { no-Nm }}{\text { no }}\right]^{1 / \mathrm{t}} \\
& \mathrm{mi}=1-\left\{\begin{array}{r}
\mathrm{b}_{1}, \mathrm{D}_{\mathrm{i}}<\mathrm{b}_{\mathrm{m}}+10 \\
\mathrm{~b}_{2}+\mathrm{b}_{3} \mathrm{D}_{\mathrm{i}}, \mathrm{D}_{1} \geq \mathrm{b}_{\mathrm{m}}+10
\end{array}\right\}
\end{aligned}
$$

$\mathrm{cm} \mathrm{dbh}$ in the forest and was modeled separately for each ecological group (equations 3 and 4).

For the annual mortality probability (equation 3 ) No is the total numbers of stems of the particular ecological group at the beginning of the time interval $t$, and $\mathrm{Nm}$ is the number of recorded dead trees during the interval. For the dynamics of the mortality model (equation 4$), b_{1} \ldots b_{3}$ are model parameters, $b_{m}$ is the bin width or $5^{\text {th }}$ percentile of the diameter distribution and $\mathrm{Di}$ is diameter at breast height of the tree $i$.

Other allometric properties, like height and crown width of the trees are determined using functions with d.b.h. These are describing extensively elsewhere along with relevant coefficient values (Phillips et al., 2004; van Gardingen et al., 2006).

\subsubsection{Dynamic equilibrium assumption model variant}

The dynamic equilibrium assumption is a very common assumption in forest dynamics modeling (Kammesheidt et al., 2001; Porte and Bartelink, 2002; Valle et al., 2009) and is generally interpreted in this context as assuming that an undisturbed forest will have a relatively stable basal area and/ or tree density on the species group level and/or the stand level. This assumption is frequently implemented by fine-tuning the forest dynamics model, regardless of whether the model is empirical or mechanistic (Valle et al., 2009).

We implemented this assumption by iteratively adjusting the parameters from the baseline growth, mortality and recruitment submodels when deemed necessary. The limits for these adjustment where the $95 \%$ confidence interval statistic for the paremeter of that curve. For the assumption to be unviolated the species group composition over a 100 -year simulation period in undisturbed forest would have to be relatively constant while compositional dynamics should be realistic in the sense that the forest managed to maintain its relative multi group composition over time without significant changes and without regression to a later or earlier stage of ecological succession.

The pragmatic justification for this procedure is that recruitment 
and mortality data are commonly problematic due to noise.

\subsubsection{The drought pulse model variant}

The drought pulse model variant is exactly the same as the dynamic equilibrium assumption model variant, except for incorporation of a steady deterministic pulse that artificially raised mortality of trees in selected ecological groups at specified intervals in time over 100-year simulations following fine tuning on the basis of the dynamic equilibrium assumption.

For the purposes of this work we defined a drought event as that event in the scale of calendar years where average dry season rainfall falls at least or more than $40 \%$ of the average annual one based on precipitation data from the long term environmental record (Williamson et al., 2000; Phillips et al., 2005)

Using this principle it was possible to establish a return interval for a drought event by an examination of rainfall gauge records dating up to 120 years before the date of this work (Haylock et al., 2006; Holmgern et al., 2001; INMET, 2001; Malhi and Phillips, 2004; Malhi and Wright, 2004; Phillips et al., 2009; Satyamurty et al., 2010; Slik, 2004; Sombroek, 2001; Vieira 2000; Williamson et al., 2000)

Following this an examination of the BDFFP permanent sample plot data spanning 23 years and encompassing two distinct drought events lead us to the conclusion that the drought pulse should essentially be a tree mortality pulse by ecological group of tree as the effect of growth is not long term significant and recruitment is a function of tree mortality (Karfakis and Andrade, 2013).

For this later analysis it was concluded that in terms of response to drought there was only two basic groups of trees: the pioneers and the non pioneers..

It was therefore decided that mortality would be applied uniformly to all groups due to the relatively small differences. The mortality increase in relation to the baseline (what mortality would have occurred if a drought had not hit the forest) for the Manaus calibration was set at $45 \%$ on a 12 year interval and for the Madre de Dios calibration for a 70\% increase every 9 years.

\subsubsection{Forest response to selective logging}

As no data from permanent sample plots where available to directly evaluate long term biomass and compositional dynamics it was decided that the response of the forest to selective logging for the two model variants both for the undisturbed forest simulations and for was to be judged intuitively using assumptions and principles in other SYMFOR modeling efforts with the same issue to be addressed (Phillips et al., 2003; Phillips et al., 2004; Valle et al., 2007) but also elsewhere (Kamesheidt et al., 2001).

Response of the forest under this criterion needs to show in general a predictable pattern of ecological succession in terms of forest stand functional composition and biomass dynamics over a 100 -year simulation period in response to a relatively severe logging event of around 12 commercial trees per hectare with a d.b.h $\geq 45 \mathrm{~cm}$.

\subsection{Design of simulations and initial conditions}

Two kinds of simulation experiments were performed. The first consisted of undisturbed forest experiments whereby for each area separately and for each one of the four hectare plots a 100 year simulation for undisturbed forest with and without a drought pulse was run and an output of tree numbers per hectare along with basal area for all individual trees for all plots was generated; The second set of experiments consisted of selective logging experiments set with two treatment with and without a drought pulse for a relatively heavy harvest of around 12 commercial trees per hectare with a d.b.h $\geq 45 \mathrm{~cm}$ for each of these. The initial ecological conditions of the forest sample plots used to initialize simulations where significantly

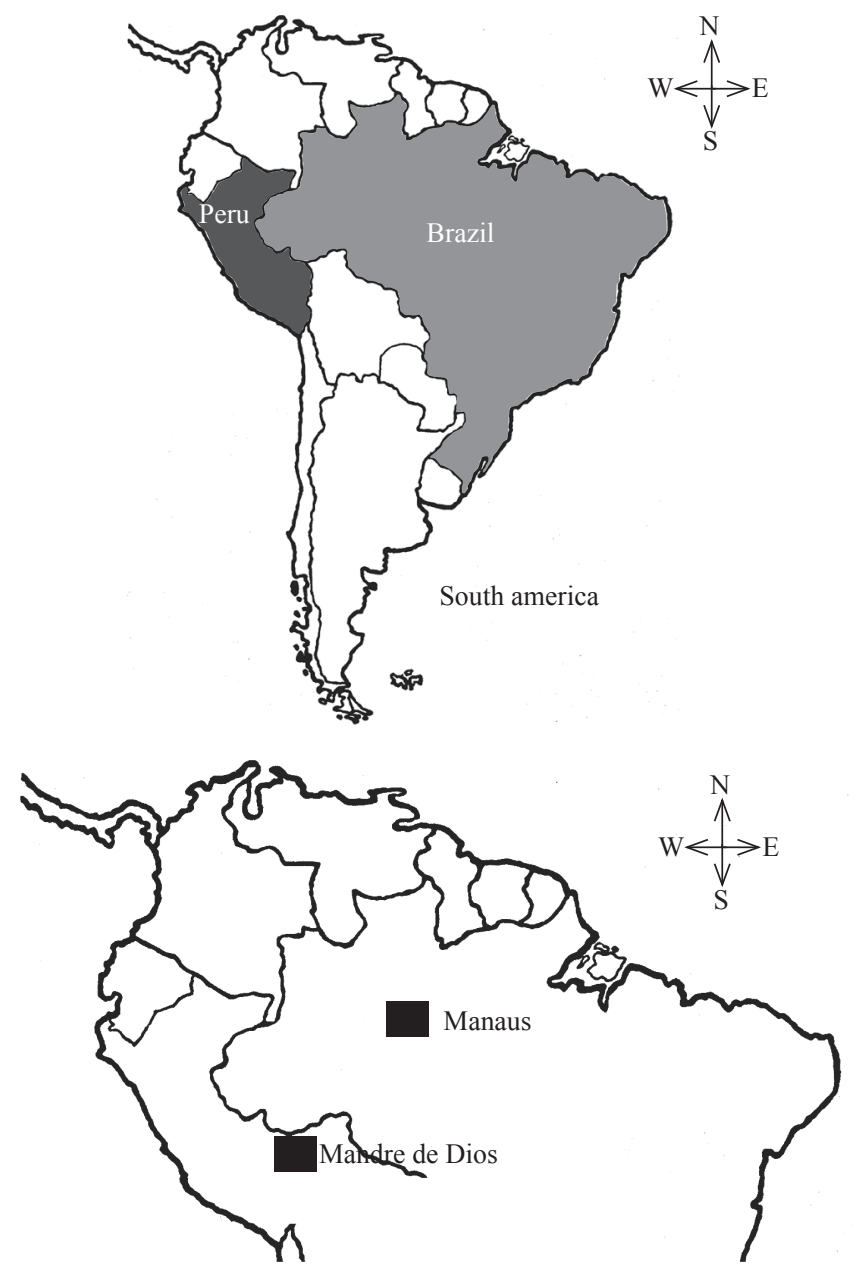

Figure 1: Location of the study areas 
different with the forest of Madre de Dios being more open in relation to the forest of the Manaus region and with respect to tree species functional composition. The forest of Madre de Dios also had a greater volume of commercial tree species and very importantly a greater proportion of more early successional heliophylic tree species (Table 2).. We used four 1 ha plots from each of the two areas. For each plot simulation was repeated 5 times, resulting in 20 repetitions. Data were output for all live trees only every fifth year to keep the size of output files manageable. We chose to output live tree basal area by ecological group as the variable which also provided us with the number of stems in each 1 ha plot. When harvesting was applied we chose to apply it not at $\mathrm{t}=0$ years but rather at $\mathrm{t}=10$ years after initializing the simulations thus giving a record of 90 years of development in response to the logging event.

\subsection{Statistical analysis}

Since the simulated datasets included repeated that strictly speaking are not independent of each other general linear models (GLM) where considered inadequate for a valid analysis. General linear mixed models (GLMM) however provide ideal solutions when measuring the same unit repeatedly through time (West et al., 1984; West et al., 1995).

These where performed using the default REML algorithm (subroutine) for examining repeated measurements data using the statistical software GENSTAT v 12.1. The variable was the number of stems per hectare by ecological group with time as an average for each one hectare plot by model version (with and without drought pulse incorporation). Separate analyses where conducted for the forests of Madre de Dios and Manaus respectively.

\section{Results and Discussion}

\subsection{Dynamic equilibrium assumption}

When the baseline model had been calibrated in the SYMFOR framework for both Manaus and Madre de Dios undisturbed forest simulations over a 100 year period showed a pattern

\begin{tabular}{lccc}
\hline \multicolumn{4}{l}{ Table 1: Ecological groups of trees used in this study } \\
\hline General ecological group & $\begin{array}{c}\text { Co- } \\
\text { de }\end{array}$ & $\begin{array}{c}\text { Wood density } \\
\left(\mathrm{g} \mathrm{cm}^{-3}\right)\end{array}$ & $\begin{array}{c}\text { Adult } \\
\text { stature }(\mathrm{m})\end{array}$ \\
\hline Slow growing emergent & 1 & $\geq 0.70$ & $\mathrm{Hmax} \geq 35$ \\
Slow growing subcanopy & 3 & $\geq 0.70$ & $\mathrm{Hmax}<15$ \\
Medium growing emergent & 4 & $0.49 \geq \mathrm{WD} \geq 0.69$ & $\mathrm{Hmax} \geq 35$ \\
Medium growing canopy & 5 & $0.49 \geq \mathrm{WD} \geq 0.69$ & $15 \geq \mathrm{Hmax} \geq 30$ \\
Medium growing subcanopy & 6 & $0.49 \geq \mathrm{WD} \geq 0.69$ & $\mathrm{Hmax}<15$ \\
Fast growing emergent & 7 & $<0.48$ & $\mathrm{Hmax} \geq 35$ \\
Fast growing canopy & 8 & $<0.48$ & $15 \geq \mathrm{Hmax} \geq 30$ \\
$\begin{array}{l}\text { Fast growing subcanopy } \\
\text { (true pioneers) }\end{array}$ & 9 & $<0.48$ & $\mathrm{Hmax}<15$ \\
\hline
\end{tabular}

that was clearly in violation of the dynamic equilibrium assumption for both the forest of the Manaus region (Figure 2a) and Madre de Dios (Figure 2b). For Manaus that the small statured medium wood density tree species showed a significant increase in mean number of (live) stems per hectare. This was also the case for the canopy trees of low wood density and high wood density canopy trees and for the true pioneers though for the later the change was much smaller. Other groups also declined and especially the high wood density emergent species group along with other minor fluctuations in other mostly later successional groups.

For the Madre de Dios baseline model there was considerable change in the number of stems per plot (hectare) and basal area per plot by species group also but changes appeared to be different to the ones of Manaus. Here there were three main groups in terms of significant increases in the forest, for high and low wood density canopy and emergent species. There were also groups that showed significant decreases and more specifically these are the medium wood density emergent and canopy species and the true pioneers.

The resulting steady state for both regions was that of a forest that would be relatively denser than that of the starting conditions dominated by groups of tree species that would not grow to emergent but mostly to that of canopy status. Also the stand would be dominated to a significant extent by more light wood density tree species.

This is a possible evolution for these forests based on a variety of finds. The most directly relevant in support of this is that of Laurance et al. (2004) which noted a gradual compositional shift during the past 20 years prior to their investigations that was expected to become more significant with time for an area of undisturbed forest near Manaus for the forest of the BDFFP from which data where obtained for the purposes of this study. The extrapolations predicted that the forest would be dominated to a greater extent by genera of light wood much the same way as the forests of the two areas based on our simulations

In addition to this there is direct evidence supporting such potential future evolution of tropical moist non-flooded forests

\begin{tabular}{lcc}
\hline $\begin{array}{l}\text { Table 2: Description of stand initial conditions considering } \\
\text { trees } \geq 10 \mathrm{~cm} \text { dbh (mean } \pm \text { standard error) }\end{array}$ & Manaus & $\begin{array}{c}\text { Madre de } \\
\text { dios }\end{array}$ \\
\hline Stand Characteristics & $311 \pm 14$ & $243 \pm 19$ \\
& $97 \pm 12$ & $136 \pm 20$ \\
\hline Total volume $\left(\mathrm{m}^{3} \mathrm{ha}^{-1}\right)$ & $3 \pm 1$ & $8 \pm 2$ \\
Commercial volume $\left(\mathrm{m}^{3} \mathrm{ha}^{-1}\right)$ & $2 \pm 0.6$ & $7 \pm 1$ \\
Percent volume of light hardwood species & \\
Percent volume of pioneer species & ** &
\end{tabular}

*Groups 7 and 8 in Table $1 ;{ }^{* *}$ Group 9 in Table 1 
from relevant studies using permanent sample plots both in the Amazon basin but also elsewhere (Baker et al., 2004; Malhi \& Phillips, 2004; Lewis et al., 2004a, 2004b).

The most likely main cause for the changes these studies point to increased plant fertilization caused by rising atmospheric pollutant concentrations such as $\mathrm{CO}_{2}$ (Baker et al., 2004; Laurance et al., 2004). However our models where entirely data constrained and it is therefore difficult to prove this assumption correct. It must also be taken under consideration that recent changes on biomass and thereby potentially composition cannot be disregarded as an artifact of the data used according to a more recent study on Amazonian plot data including several datasets that were used in this study (Gloor et al., 2009). However equally compelling evidence from similar forests elsewhere suggests that this is simply a pattern of common natural fluctuations in the relevant dynamics of the forests for both biomass and functional composition as is evident for two large forest plots in Malaysia and Panama (Feeley et al., 2007).

In addition to this such changes can potentially be entirely an artifact of the data due to the almost universal issue of significant amount of noise of these used in parameterization (Phillips et al., 2002; Phillips et al., 2003; Phillips et al., 2004; Vale et al., 2009), especially mortality and recruitment .

It is known however that changes of this magnitude have not yet occurred for the forests of the Manaus region (Karfakis\& Andrade 2013).

Moreover Phillips et al. (2004) for a similar modeling effort

\begin{tabular}{|c|c|c|c|c|c|c|}
\hline \multicolumn{7}{|c|}{ Table A1: Parameters for the growth model for both model variants } \\
\hline & Group & $\mathrm{a}_{0}$ & $\mathrm{a}_{1}$ & $\mathrm{a}_{2}$ & $\mathrm{a}_{3}$ & $\mathrm{a}_{4}$ \\
\hline \multirow{9}{*}{$\begin{array}{l}n \\
0 \\
J \\
\Xi \\
\tilde{J} \\
\sum\end{array}$} & 1 & 0.0004 & 0.0001 & 3.178 & -0.0177 & 0.202 \\
\hline & 2 & 0.0001 & 0.0004 & 2.388 & -0.055 & 0.217 \\
\hline & 3 & 0.0054 & -0.0005 & 2.101 & 0.0417 & 0.1114 \\
\hline & 4 & 0.0023 & 0.00001 & 4.28 & -0.0522 & 0.212 \\
\hline & 5 & 0.007 & -0.002 & 3.188 & -0.0533 & 0.165 \\
\hline & 6 & 0.0055 & -0.0004 & 2.0633 & -0.0037 & 0.161 \\
\hline & 7 & 0.0038 & -0.0002 & 5.776 & -0.106 & 0.258 \\
\hline & 8 & 0.0073 & -0.0009 & 2.54 & -0.137 & 0.270 \\
\hline & 9 & 0.282 & -0.0005 & 0.0211 & -0.058 & 0.0018 \\
\hline \multirow{9}{*}{$\begin{array}{l}n \\
0 \\
0 \\
0 \\
0 \\
0 \\
0 \\
0 \\
0 \\
0 \\
\Sigma\end{array}$} & 1 & -0.0034 & 0.1 & 0.1 & -0.093 & 0.059 \\
\hline & 2 & -0.0054 & 0.1 & 0.1 & -0.213 & 0.0185 \\
\hline & 3 & -0.15 & 0.1 & 0.1 & -0.156 & 0.088 \\
\hline & 4 & -0.0043 & 0.1 & 0.1 & -0.117 & 0.25 \\
\hline & 5 & -0.0095 & 0.1 & 0.1 & -0.078 & 0.16 \\
\hline & 6 & -0.027 & 0.1 & 0.1 & -0.2 & 0.19 \\
\hline & 7 & -0.0034 & 0.1 & 0.1 & -0.11 & -0.0038 \\
\hline & 8 & -0.0039 & 0.1 & 0.1 & -0.158 & 0.153 \\
\hline & 9 & -0.0063 & 0.1 & 0.1 & -0.0148 & 0.133 \\
\hline
\end{tabular}

and associated ecological grouping system in the SYMFOR framework for non-flooded tropical forest in Para state, Brazil hypothesized that this causes pioneers or associated groups to consistently outperform more lately successional shade tolerant species due to their inherently faster recruitment rates. This was in particular because they outperformed more shade tolerant species in gaps in natural forest. They also hypothesized that this was because they did not have an adequate area of undisturbed forest that was monitored and hence natural gaps. They proceeded into empirical fine tuning on the basis of this assumption.

Based on current scientific evidence we therefore concluded that these dynamics where in direct violation of the dynamic equilibrium assumption in both cases and proceeded in changing selected model parameters empirically through the process of fine tuning so that the baseline models agree to the dynamic equilibrium assumption as was the common practice in other efforts in the SYMFOR framework .

For the Manaus version this resulted in a steady state in which although some compositional changes occurred these remained within the limits of the forest plot data used to initialize simulations This was also the case for the Puerto Maldonado version. These results were also in agreement with other studies (Arets, 2005; Phillips et al., 2002; Phillips et al., 2004; Valle et al., 2007).

In response to a heavy single logging event the forests of both Manaus and Puerto Maldonado exhibited significant compositional and biomass changes in response to logging.

Table A2: Parameters for the mortality and recruitment models for both model variants

\begin{tabular}{|c|c|c|c|c|c|c|c|c|}
\hline & Group & $\mathrm{r}_{1}$ & $\mathrm{r}_{2}$ & $\mathrm{Ti}$ & $\mathrm{b}_{1}$ & $\mathrm{~b}_{2}$ & $\mathrm{~b}_{3}$ & $\operatorname{Bin}(\mathrm{cm})$ \\
\hline \multirow{9}{*}{$\begin{array}{l}\infty \\
0 \\
\vdots \\
\Xi \\
\Xi \\
\pi \\
\Sigma\end{array}$} & 1 & -1.41 & 0.0074 & 49.4 & 1.76 & 0.0037 & 0.0396 & 2.6 \\
\hline & 2 & 0.0749 & 0.0021 & 52 & 2.2 & -0.0039 & 0.944 & 4.4 \\
\hline & 3 & -2.351 & 0.004 & 65 & 1.44 & -0.0137 & 1.0 & 3.5 \\
\hline & 4 & -2.862 & 0.024 & 40 & 1.36 & -0.0069 & 0.011 & 1.5 \\
\hline & 5 & -0.021 & 0.0329 & 45 & 5.166 & 0.0053 & 0.933 & 7.5 \\
\hline & 6 & 0.823 & -0.0088 & 50 & 8.13 & -0.0209 & 4.32 & 5.3 \\
\hline & 7 & -0.104 & 0.0246 & 35 & 7.128 & -0.0091 & 1.7 & 3.5 \\
\hline & 8 & 0.2658 & -0.0246 & 32.1 & 8.3216 & -0.0156 & 1.807 & 3.3 \\
\hline & 9 & 0.479 & -0.0002 & 22 & 8.379 & 0.2694 & 2.27 & 2.4 \\
\hline \multirow{3}{*}{ 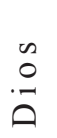 } & 1 & 0.014 & 0.0012 & 50 & 0.8372 & -0.0132 & 1.421 & 1.9 \\
\hline & 2 & 0.0574 & 0.0011 & 30 & 1.4396 & -0.0076 & 1.3225 & 3.3 \\
\hline & 3 & 0.2394 & -0.0176 & 43 & 1.09 & 0.0243 & 0.0406 & 4.1 \\
\hline \multirow{6}{*}{ 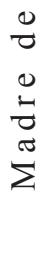 } & 4 & -0.0434 & -0.3869 & 55 & 0.875 & -0.0093 & 0.5175 & 2.2 \\
\hline & 5 & -0.1723 & -0.1496 & 33 & 1.6133 & -0.0175 & 0.74 & 1.9 \\
\hline & 6 & -0.5416 & 0.03 & 43 & 1.19 & 0.0284 & 0.132 & 5.2 \\
\hline & 7 & 0.0 & 0.011 & 16 & 2.4 & -0.0151 & 2.5574 & 2.7 \\
\hline & 8 & 0.0 & 0.00159 & 11 & 1.525 & -0.0181 & 2.7868 & 2.1 \\
\hline & 9 & -0.1782 & 0.0904 & 12 & 1.898 & -0.0491 & 5.57 & 3.9 \\
\hline
\end{tabular}


More specifically more early successional species groups benefited at the expense of more late successional ones. Following the logging event succession towards a steady state dominated to a greater extent by more shade loving early successional species with a higher wood density followed for both the Manaus region(Figure 3a) and Madre de Dios (Figure 3b).

These results were also in agreement with other studies within SYMFOR(Arets, 2005; Phillips et al., 2002; Phillips et al., 2004; Valle et al., 2009) but also elsewhere (Carreno-Rocabado et al., 2012; . Horne and Gwalter, 1982; Kamesheidt et al., 2000; Kariuki, 2004)

Estimates of the model parameters for the growth, mortality and recruitment submodels for both Manaus and Madre de Dios are

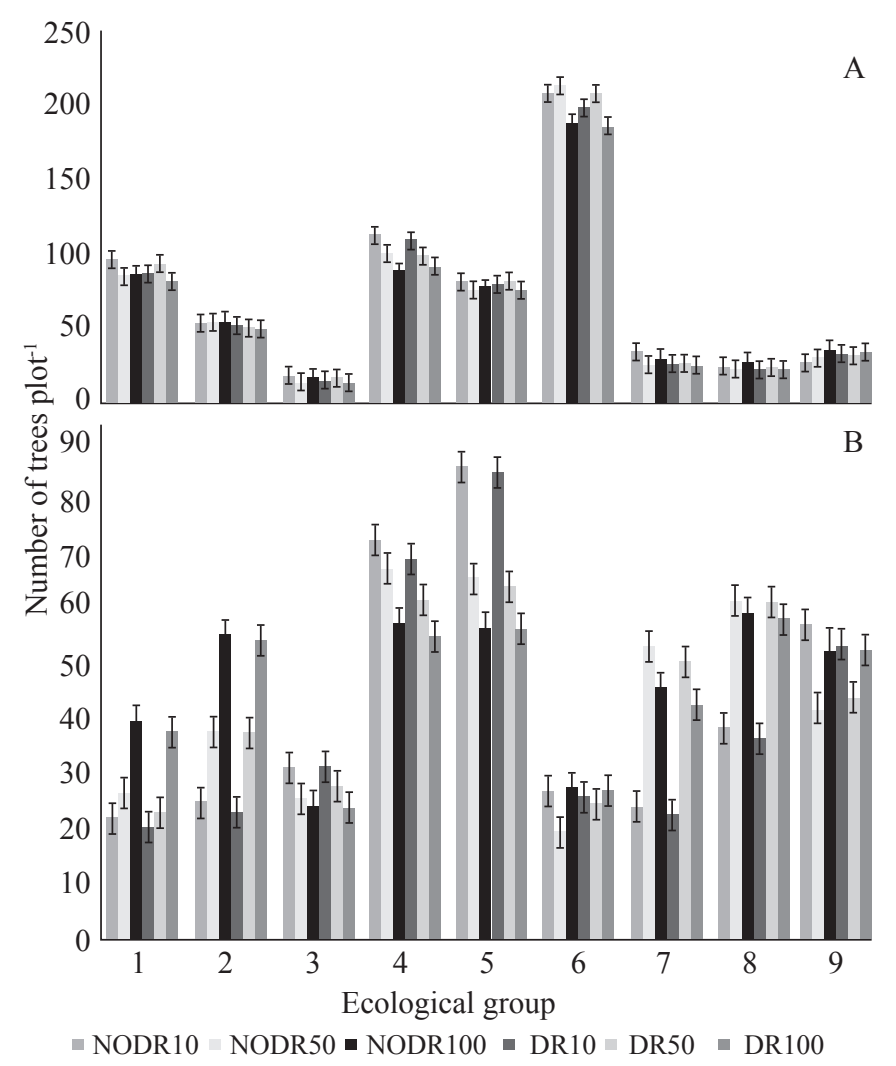

Figure 2: Forest dynamics of 9 ecological groups of trees (horizontal axis) expressed as number of trees (live stems) per hectare (vertical axis) considering trees $\geq 10 \mathrm{~cm}$ dbh. This is following fine tuning based on the dynamic equilibrium assumption across a 100 year simulation period divided in three time points : 10,50 and 100 years after the beginning of the simulations for a model version without drought pulse :NODR $10=$ year 10 , NODR $50=$ year 50, NODR 100=year 100 and with drought pulse incorporated :DR 10=year 10, DR 50=year 50, DR 100=year 100. Forest not subjected to logging for Manaus (A) and Madre de Dios (B). Error bars represent standard error of the mean. given in tables A1 and A2 respectively in Appendix A.

\subsection{Drought pulse Assumption}

The incorporation of a drought pulse had a significant effect on both undisturbed forest dynamics and one subjected to heavy logging (Table 3). The effect on the undisturbed forest simulations was that of a decrease in the number of stems (live stems) per hectare (Figure 4). This was also true for selectively logged forest with time period as factor. Again the effect was similar for both Manaus (Figure 2B) and Madre de Dios (Figure 3B).

It was therefore evident that the incorporation of the drought pulse had a significant influence on the simulation output from

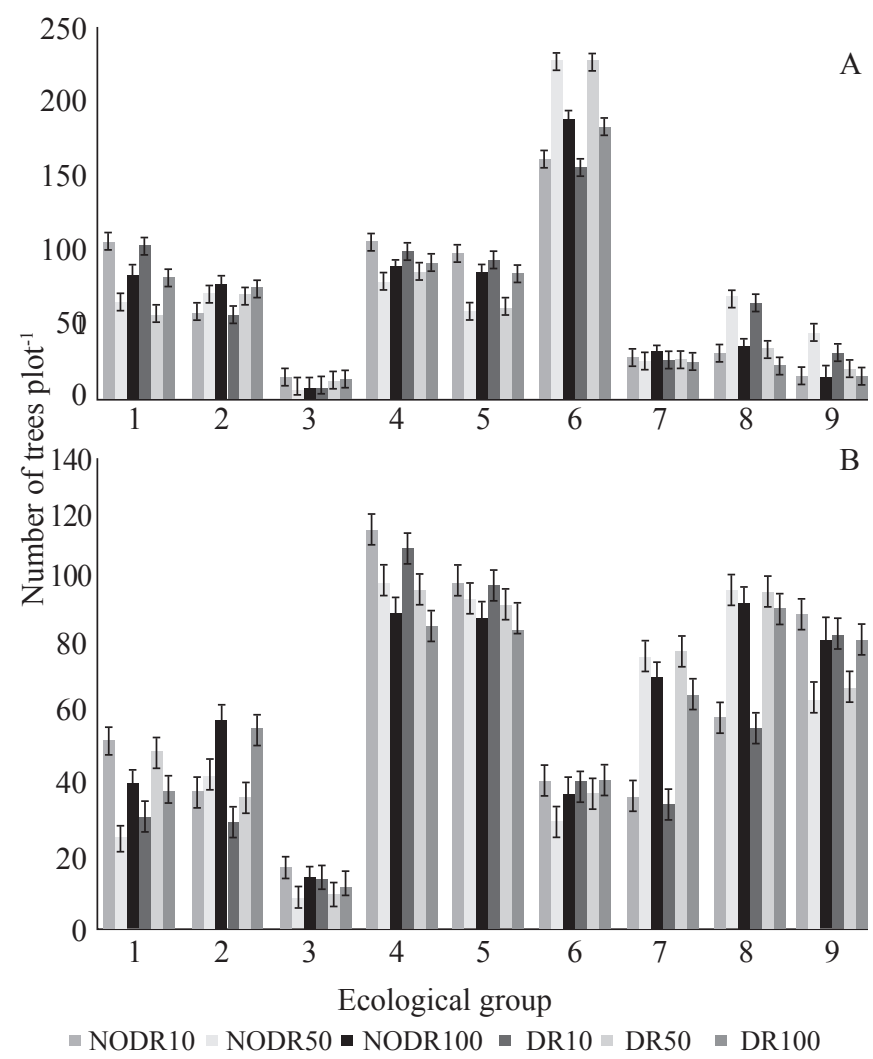

Figure 3: Forest dynamics of 9 ecological groups of trees (horizontal axis) expressed as number of trees (live stems) per hectare (vertical axis) considering trees $\geq 10 \mathrm{~cm}$ dbh. This is following fine tuning based on the dynamic equilibrium assumption across a 100 year simulation period divided in three time points:10,50 and 100 years after the beginning of the simulations for a model version without drought pulse :NODR $10=$ year 10 , NODR 50=year 50, NODR $100=$ year 100 and with drought pulse incorporated:DR 10=year 10, DR 50=year 50 , DR $100=$ year 100 . Forest subjected to a relatively severe logging event ( $15 \mathrm{stems} \geq 45 \mathrm{~cm}$ dbh per hectare) at year 10 of simulations For Manaus (A) and Madre de Dios (B). Error bars represent standard error of the mean. 
both model versions though for the Manaus model the effect appeared to be more significant than Madre de Dios. From available analyses no effect on the compositional dynamics of the forest could be determined. More specifically it was apparent that the effect of the pulse could not promote or suppress significantly the population density of any of the groups during the simulated period in the unlogged primary forest. Therefore it was not possible to prove that current species richness of these tropical rainforest sites is directly related to drought despite direct correlation observed from field data (ter Steege et al., 2003). The effect of competition appears to be highly significant and is in contradiction with the finds and opinions of Bamphlyde et al. (2005) that factors other than competition and potentially exogenous ones are more important in maintaining current species richness observed in tropical rainforests.

In contrast to functional composition there was a significant effect on the total number of stems per hectare for the forest stand as a whole. More specifically the steady state number of stems per hectare was consistently smaller with a drought pulse than without one (Figure 4). Furthermore this was considerably closer to the values derived from permanent sample plot data from each region but also the initial conditions prior the commencement of the simulations. This is not surprising as the drought essentially increases the overall tree mortality levels (Gloor et al., 2009; Holmgern et al., 2001)

Therefore increased conformation to relevant field data is not surprising. This was the case for both areas but appeared to be more significant for Madre de Dios. This is also not surprising because it is known that drought is a much stronger ecological component of these forests (ter Steege et al., 2003; Phillips et al., 2005; Satyyamurty et al., 2010).

For both areas despite the fact that tree density in the steady

Table 3: F-statistic and $\mathrm{P}$ values for the GLMM analysis for number of live stems per hectare

\begin{tabular}{lccc}
\hline Treatment & Variable & F-statistic & P value \\
\hline Manaus & Ecological group & 11.52 & $<0.001$ \\
Undisturbed & All stems $\geq 10 \mathrm{~cm} \mathrm{dbh}$ & 78.38 & $<0.001$ \\
forest & & & \\
& & & \\
Manaus & Ecological group & 7.980 & $<0.001$ \\
logged & All stems $\geq 10 \mathrm{~cm} \mathrm{dbh}$ & 58.91 & $<0.001$ \\
Forest & Ecological group & 2.7000 & $<0.001$ \\
Madre de & All stems $\geq 10 \mathrm{~cm} \mathrm{dbh}$ & 0.370 & $<0.001$ \\
$\begin{array}{l}\text { Dios Undis- } \\
\text { turbed forest }\end{array}$ & Ecological group & 9.340 & $<0.001$ \\
All stems $\geq 10 \mathrm{~cm} \mathrm{dbh}$ & 15.78 & $<0.001$ \\
Madre de dios & & & \\
logged forest & & & \\
\hline
\end{tabular}

state forest is reduced to levels closer to field data it still remains more elevated relatively. This is potentially because other forms of natural disturbance such as animal browsing are not represented at all in the current model.

For selectively logged forest it appeared for both areas that the increased baseline (natural) mortality of trees causes recovery of biomass to occur later than without it (Figure 5).

This is an expected result with important implications for use of these models in decision making for sustainable forest management and more specifically yield regulation. This is because this process needs to be very accurate and underestimation of baseline mortality will naturally overestimate yield (Alder, 1995; Vanclay, 1995).

Results were in general almost identical to the dynamic equilibrium assumption model variant for undisturbed forest and selectively logged forest and were also in agreement with studies within SYMFOR but also elsewhere for both undisturbed (Arets, 2005; Phillips et al., 2002; Phillips et al., 2004; Valle et al., 2007) and selectively logged forest (Arets, 2005; Phillips et al., 2002; Phillips et al., 2004; Valle et al.,

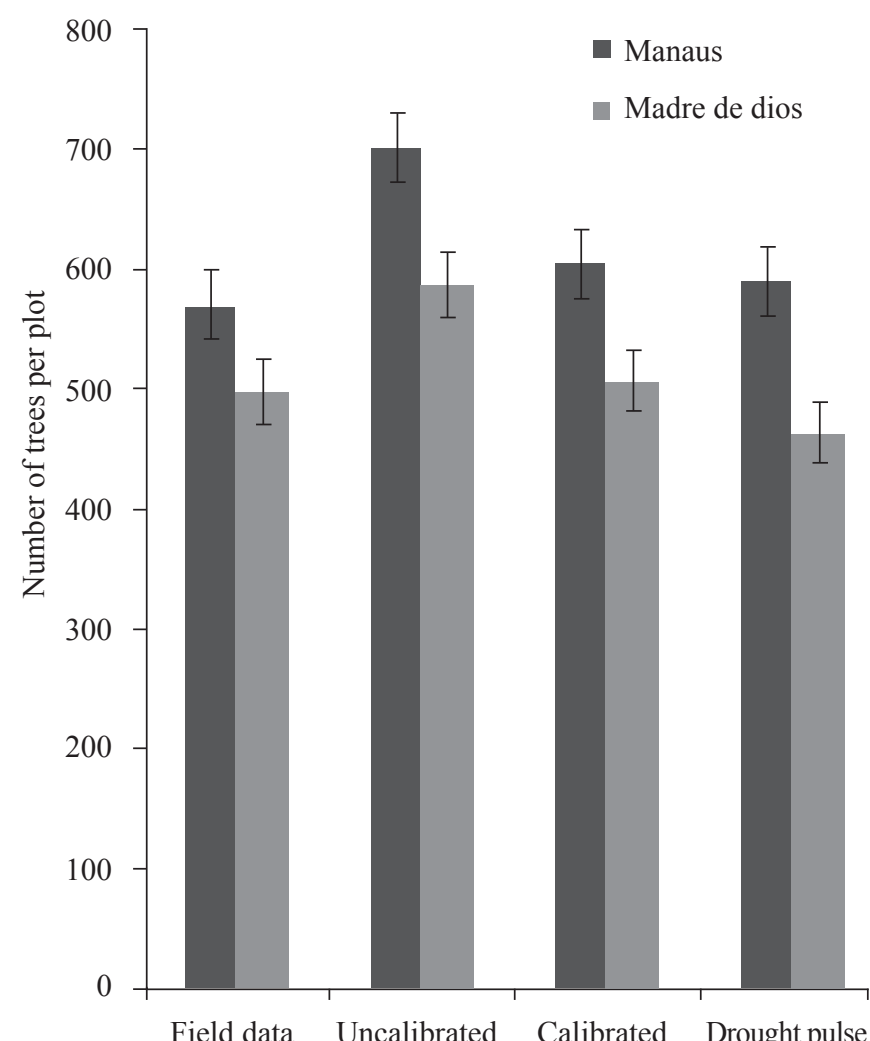

Figure 4: Stand density expressed as mean number of live stems $\geq 10 \mathrm{~cm}$ dbh per hectare over a 100 year simulation period of the forest of Madre de Dios and the Manaus regions from field data and for the steady state of the undisturbed forest for both model versions for the uncalibrated, calibrated and the drought pulse versions. 


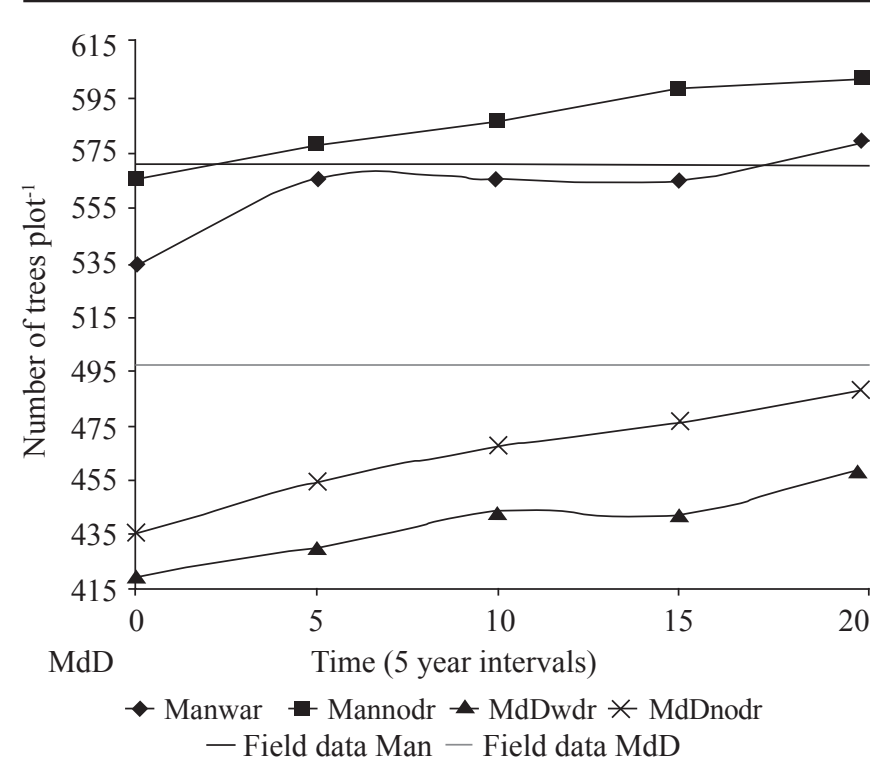

Figure 5: Modeled evolution of stand density over a 100 year simulation period (expressed as mean number of live stems per hectare) considering trees $\geq 10 \mathrm{~cm}$ dbh in response to a relatively heavy single selective logging event (around 12 trees $\geq 45 \mathrm{~cm}$ dbh per hectare). For the forests of the Manaus and Madre de Dios regions in relation to field data from harvested undisturbed forest stands from both regions. Field data: Man=Manaus; $\mathrm{MdD}=$ Madre de Dios. Model variant: Manwdr=Manaus drought pulse; Mannodr=Manaus without drought pulse; MdDwdr=Madre de Dios drought pulse; $M d D=$ Madre de Dios without drought pulse.

2009; Carreno-Rocabado et al., 2012; . Horne and Gwalter, 1982; Kamesheidt et al., 2000; Kariuki, 2004). Results where also in agreement with graphical analyses of model output for both model variants for stem density and basal area by ecological group with time of Karfakis et al. (2013) that also concluded this variant to be realistic with respect to undisturbed forest dynamics and response to selective logging

\section{Conclusions}

The incorporation of a drought stress pulse had a significant effect on forest dynamics because of its influence of bringing the biomass dynamics much closer to levels found in permanent sample plot data. It did not however have a significant impact on the compositional dynamics of the forest in the undisturbed state and in response to selective logging. These results lead us to reject the null hypothesis as there was no significant difference between the two model variants with respect to forest functional composition despite the significant effect on biomass dynamics observed.

\section{Acknowledgments}

The authors wish to thank the Biological Dynamics of Forest
Fragments Project, the Large scale Program for Research in Biodiversity and Precious Woods Amazonas ltd for kindly allowing access to their phytodemographic database. We would also like to thank the SALVIAS project as well as RAINFOR consortium for kindly allowing access to the use of portions of the data from the Tambopata and Cuzco Amazonas plot sites for the first and second census respectively. Finally we would like to acknowledge the use of the TEAM network for nature early warning system for nature phytodemographic datasets for the Manaus site available freely on the internet.

\section{References}

Arets, J.M.E., 2005. Long term responses of populations and communities of trees to selective logging in tropical rainforests in Guyana. $\mathrm{PhD}$ thesis, Wageningen Agricultural University, the Netherlands.

Baker, T.R., Phillips, O.L., Malhi, Y., Almeida, S., Arroyo, L., Di Fiore, A., Erwin, T., Higuchi, N., Killeen, T.J., Laurance, S.G., Laurance, W.F., Lewis, S.L., Monteagudo, A., Neill, D.A., Nunez Vargaz, P., Pitman, N.C.A., Silva, J.N.M., Vasquez Martinez, R., (2004). Increasing biomass in Amazonian forest plots. Philosophical Transactions of the Royal Society of London Series-B, Biological Sciences 359, 353-365.

Bamphylde, C., Brown, N.D., Gavaghan, D.J., Maini, P.K., 2005. Modeling rain forest diversity: The role of competition. Ecological Modeling 188, 253-278.

Burrows, C.J.A., 2000. Processes of vegetation change. UNWIND-Human publications.

de Castilho, C.V., Magnusson, W.E., de Araujo, R.N.O., Luziao, R.C.C., Lima, A.P. Higuchi, N., 2006. Variation in aboveground tree live biomass in a central Amazonian Forest: Effects of soil and topography. Forest Ecology and Management 234, 85-96.

da Silva, E.J.V., 2004. Dynamics of management and conventionally logged forests in the Eastern Amazon .Unpublished PhD thesis, School of Engineering, State University of Sao Paolo, Brazil.

Carreno-Rocabado, G., Pena-Claros M., Bongers F., Alarcon A., Licona J., Poorter, L., 2012. Effects of disturbance intensity on species and functional diversity in a tropical forest. Journal of Ecology, 100, 1453-1463.

Erwin, T., 1985. Tambopata Reserved Zone, Madre de Dios, Peru: History and description of the Reserve. Revista Peruana de Entomologia 27, 1-8.

Feeley, K.J., Wright, S.J., Nur Supardi, M.N., Rahman Kassim, A., Davies, S.J., 2007. Decelerating growth in tropical forest trees. Ecology Letters 10, 461-469

Gloor, M., Phillips, O.L., Lloyd, J.J., Lewis, S.L., Malhi, Y., Baker, T.R., Lopez-Gonzalez, G., Peacock, J., Almeida, S., Alves-de Oliveira, A.C., Alvarez, E., Amaral, I., 
Arroyo, L., Aymard, G., Banki, O., Blanc, L., Bonal, D., Brandos, P., Chao, K.J., Chave, J., Davila, N., Erwin, T., Silva, J., Di Fiore, A., Feldpausch, T., Freitas, A., Herrera, R., Higuchi, N., Honorio, E., Jimenez, E., Killeen, T., Laurance, W., Mendoza, C., Monteagudo, A., Andrade, A., Neill, D., Nepstad, D., Nunez-Vargas, P., Penuela, M.C., Pena-Cruz, A., Prieto, A., Pitman, N., Quesada, C., Salomao, R., Silveira, M., Schwarz, M., Stropp, J., Ramirez, F., Ramirez, H., Rudas, A., ter steege, H., Silva, N., Torres, A., Terborgh, J., Vasquez, R., Van der Heiden, G., (2009). Does the disturbance hypothesis explain the biomass increase in basin-wide Amazon forest plot data? Global Change Biology 10, 1-13.

Holdridge, L.R., 1978. Determination of world plant formations from simple climatic data. Science 105(2727), 367-8.

Horne, R., Gwalter, J., 1982a. The recovery of rainforest following logging. 1. Subtropical rainforest. Aust. Forest Res. 13, 29-44.

Horne, R., Gwalter, J., 1982b.The recovery of rainforest following logging. 2. Tropical rainforest. Aust. Forest Res. 13, 45-59.

Karfakis, T.N.S., Andrade, A., 2013. Dynamics of functional composition of a Brazilian tropical forest in response to drought stress. World Academy of Science, Engineering and Technology 75, 693-697.

Karfakis, T.N.S., Andrade, A.,Volkmer-Castilho, C.,Valle, D.R., Arets, E., van Gardingen, P., 2013.Modeling the effects of type and intensity of selective logging on forests of the Amazon. World Academy of Science, Engineering and Technology 79, 1776-1786.

Kammesheidt, L., Kholer, P., Huth, A., 2001. Sustainable timber harvesting in Venezuela: A modeling approach. Journal of applied ecology 38, 756-770.

Kariuki, M., 2004. Modeling dynamics including recruitment, growth and mortality for sustainable management in uneven-aged mixed-species rainforests. Unpublished $\mathrm{PhD}$ thesis, Southern Cross University, NSW Australia.

Kohler, P., Ditzer, T., Huth, A., 2000. Concepts for the aggregation of tropical tree species into functional types and the application to Sabah's lowland rain forests. J. Trop. Ecol 16, 591-602.

Lewis, S.L., Phillips, O.L., Baker, T.R., Lloyd, J., Malhi, Y., Almeida, S., Higuchi, N., Laurance, W.F., Neill, D.A., Silva, J.N.M., Terborgh, J., Lezama, A.T., Martinez, R.V., Brown, S., Chave, J., Kuebler, C., Vargas, P.N., Vinceti, B., 2004. Concerted changes in tropical forest structure and dynamics: evidence from 50 South American longterm plots. Philosophical Transactions of the Royal Society of London Series B-Biological Sciences 359, 421-436.

Lewis, S., Lopez-Gonzalez, G., Bonaventure, S., Affum-Baffoe,
K., Baker, T.R., Ojo, O.L., Phillips, O.L., Reitsma, J.M., White, L., Comiskey, J.A., Djuikouo, K., Ewango, C.E.N., Feldpausch, T.R., Hamilton, A.C., Gloor, M., Hart, T., Hladik, A., Loyd, J., Lovett, J.C., Makana, J.R., Malhi, Y., Mbago, F.M., Ndangalasi, H.J., Peacock, J., S.H., Peh, K., Sheil, D., Sunderland, D., Swaine, M.D., Taplin, J., Taylor, D., Thomas, S.C., Votere, R., Hansrjig, W., 2009. Increasing carbon storage in intact African tropical forests, Nature, 457, 1003-1007.

Malhi, Y., Phillips, O.L., 2004. Tropical forests and global atmospheric change: a synthesis. Philosophical Transactions of the Royal Society of London Series B-Biological Sciences 359, 549-555.

Malhi, Y., Baker, T.R., Phillips, O.L., Almeida, S., Alvarez, E., Arroyo, L., Chave, J., Czimczic, C.I., Di Fiore, A., Higuchi, N., Kileen, T.J., Laurance, S., Laurance, W., Lewis, S., Mercado-Montoya, M., Monteagudo, A., Neill, D.A., Quesada, P., Salomao, R., Silva, J.N.M., Lezzama-Torres, A., Vasquez-Martinez, R., Terborgh, J., Vincenti, B., Lloyd, J., 2004. The above-ground coarse woody productivity of 104 Neotropical forest plots. Global change Biology 10, 563-591.

Nelson, B.W., Kapos, V., Adams, J.B., Oliveira, W.J., Braun, O.P.G., 1994. Forest Disturbance by Large Blow downs in the Brazilian Amazon. Ecology 75, 853-858.

Phillips, P.D., Khan, M.T., Singh, J., van Gardingen, P., 2002 b. An Ecological model for the management of natural forests derived from the Barama Company Limited plots in NW Guyana. SYMFOR technical note series 11.

Phillips, P.D., de Azevedo, C.P., Degen, B., Thompson, I.S., Silva, J.N.M., van Gardingen, P., 2004. An individualbased spatially explicit simulation model for strategic forest management planning in the Eastern Amazon. Ecological modelling 17, 335-354.

Phillips, O.L., Aragao, L.E.O.C., Lewis, S.L., Fisher, J.B., Lloyd, J., Lopez-Gonzalez, G., Malhi, Y., Monteagudo, A., Peacock, J., Quesada, C.A., van der Heijden, G., Almeida, S., Amaral, I., Arroyo, L., Aymard, G., Baker, T.R., Banki, O., Blanc, L., Bonal, D., Brando, P., Chave, J., Alves de Oliveira, A.C., Cardozo, N.D., Czimczik, C.I., Feldpausch, T.R., Aparecida Freitas, M., Gloor, E., Higuchi, N., Jimenez, E., Lloyd, G., Meir, P., Mendoza, C., Morel, A., Neill, D.A., Nepstad, D., Patino, S., Penuela, M.C., Prieto, A., Ramirez, F., Schwarz, M., Silva, J., Silveira, M., Sota Thomas, A., ter Steege, H., Stropp, J., Vasquez, R., Zelazowski, P., Alvarez Davila, E., Andelman, S., Andrade, A., Chao, K., Erwin, T., Di Fiore, A., Honorio, C.E., Keeling, H., Killeen, T.J., Laurance, W.F., Pena Cruz, A., Pitman, N.C.A., Nunez Vargas, P., Ramirez-Angulo, H., Rudas, A., Salamao, R, Silva, N., Terborgh, J., Torres-Lezama, A., 2009. 
Drought Sensitivity of the Amazon Rainforest. Science, 323, 1344-1347.

Phillips, P.D., van Gardingen, P.R., 2001. The SYMFOR framework for individual-based spatial ecological and silvicultural forest models. SYMFOR Technical Notes Series No. 8, The University of Edinburgh, United Kingdom.

Porte, A., Bartelink, H.H., 2002. Modeling mixed forest growth: a review of models for forest management. Ecol. Model. 150, 141-188.

Quesada, C.A., Lloyd, J., Schwarz, M., Pati, S., Baker, T.R., Czimczik, C., Fyllas, N.M., Martinelli, L., Nardoto, G.B., Schmerler, J.,. Santos, A.J.B., Hodnett, M.G., Herrera, R, Luizao, F.J., Arneth, A., Lloyd, G., Dezzeo, N., Hilke, I., Kuhlmann, I., Raessler, M., Brand, W.A., Geilmann, H., Moraes Filho, J.O., Carvalho, F.P., Araujo Filho, R.N., Chaves J.E., Cruz Junior, O.F., Pimentel, T.P., Paiva, R., 2007.Variations in chemical and physical properties of Amazon forest soils in relation to their genesis. Biogeosciences. 7, 1515-1541.

Satyamurty, P., Anderson-De Castro, A., Tota, J., Eliane da Silva., Gularte, L., Ocimar-Manzi, A., 2010. Rainfall trends in the Brazilian Amazon Basin in the past eight decades. Theoretical and applied climatology 99, 139-148.

Sombroek, W., 2001. Spatial and temporal patterns of Amazon rainfall. Ambio 30, 388-396.

ter Steege, H., Pitman, N., Sabatier, D., Castellanos, H., van der Hout, P., Daly, D.C., Silveira, M., Phillips, O., Vasquez, R., Van Andel, T., Duivenvoorden, J., de Oliveira, A.A., Ek, R., Lilwah, R., Thomas, R., van Essen, J., Baider, C., Maas, P., Mori, S., Terborgh, J., Nunez Vargaz, P., Mogollon, H., Morawetz, W., 2003. A spatial model of tree $\alpha$-diversity and tree density for the Amazon. Biodiversity and Conservation 12, 2255-2277.
Valle, D., Phillips, P., Vidal, E., Schulze, M., Grogan, J., Sales M., van Gardingen, P., 2007. Adaptation of a spatially explicit individual tree-based growth and yield model and long-term comparison between reduced-impact and conventional logging in eastern Amazonia, Brazil. Forest Ecology and Management. 243, 187-198.

Valle, D., Staudhammer, L.C., Cropper, P.W., van Gardingen, P.R., 2009. The importance of multimodel projections to assess uncertainty in projections from simulation models: Case study in the SYMFOR modeling framework. Ecological applications 19, 1680-1692.

Van Dam, O., 2001. Forest filled with gaps: effects of gap size on water and nutrient cycling in tropical rain forest -A study in Guyana. Ph.D. thesis, Utrecht University. Tropenbos-Guyana Series 10, Tropenbos-Guyana Program, Georgetown, Guyana.

Vanclay, J., 1995. Modelling forest growth and yield: application to mixed tropical rainforests. CABI publishing.

West, P.W., Ratkowsky, D.A., Davis, A.W., 1984. Problems of hypothesis testing of regressions with multiple measurements from individual sampling units. For. Ecol. Manage. 7, 207-224.

West, P.W., 1995. Application of regression analysis to inventory data with measurements on successive occasions. Forest ecology and Management. 71, 227-234.

.Wellhofer, S., 2002.Environmentally sound forest harvesting in Brazil- Assessment of regeneration and environmental impacts four years after harvesting. Forest harvesting case study 19, FAO.

Williamson, B., Laurance, W.F., Oliveira, A., Delamonica, P., Gauscon, C., Lovejoy, T., Pohl, L., 2000. Amazonian tree mortality during the 1997 El Nino drought. Conservation Biology 14(5), 1538-1542. 